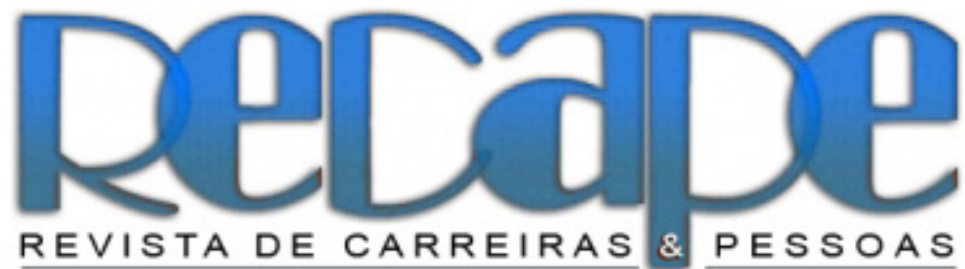

ISSN: 2237-1427

v. 10, n. 2,2020

$$
\mid
$$

\title{
EDITORIAL - INNOVATION AND ORGANIZATION
}

After all, how does the Brazilian worker behave when he needs to innovate? In organizations, the pressure to produce in a "new way" can reach the market - the competitor does it better or the consumer doesn't want that format anymore. However, it can also be formed by an endogenous profile, in the daily life of organizations, which at some point awakens, in an improvised or evolutionary way, to any need to innovate. Which of these origins is most incidental to the will to innovate?

It is indisputable that other exogenous factors also pave the way for innovation in organizations. From changes in the legal apparatus, to incessant technological innovations - which appear and impose themselves, without any limit - redefining, often completely, the entire cost structure of the business. How to recognize the worker's aptitude to live with so many attitudes of innovation?

Without forgetting that among the exogenous pressures for change, there are, of course, the infinite possibilities for the advancement of knowledge, especially the academic one, offering new formats of human coexistence to the organizational environment. And, there is also the issue of "personal values" that have a significant influence on the construction of innovations in the corporate world.

In this context, in which there are so many variables and formats of pressure for change in the business scenario, the relationship between innovation and organization has become the thematic axis of the second issue of Volume 10 of Revista de Carreiras e Pessoa.

The article that opens this edition, "The Measure of the attitude of innovation: Metric Values, factor invariance and differences in workers", by professors Nilton Soares Formiga, from Potiguar University, Bruna Gonçalves de Oliveira Freire, from State University of Rio Grande do Norte and Antonio Fernandes, from the University of Aveiro, Portugal, part of the perception that companies are increasingly trying to understand variables that can influence the innovative behavior of workers. The objective of the article is to verify the psychometric quality of a scale of innovative attitudes for 
the Brazilian context. The proposal is interesting because in Brazil few studies specifically target "Subject", professional performance with "innovative performance".

The sample selected in the study was designed in two phases. The first, with 200 questionnaires, met the exploratory factor analysis; the second, with 212 respondents, was used for confirmatory and convergence analysis. In methodological terms, the research is a descriptive, exploratory and correlational study, of a quantitative nature, which worked with validated questionnaires measuring the Scale of Attitudes of Innovation (EAI), Scale of Perception of Organizational Support (EPSO), Scale of Professional Satisfaction (STP ). The results obtained indicated the psychometric quality of the measurement, both in its exploratory and confirmatory stages. They also demonstrated their influence on the organizational support and job satisfaction of the workers surveyed.

The second article in this edition, "Personal values and meanings attributed to work by graduates of Public Administration", by researcher Fabiana Pinto de Almeida Bizarria Correio and professor Alexandre Oliveira Lima, both from the University of International Integration of Afro-Brazilian Lusophony, and from Professor Antonia Márcia Rodrigues Sousa, from the Federal University of Ceará, aims to analyze how the meanings attributed to work reflect personal values. In theoretical terms, in the article, the meaning of work occurs through the socialization process and through active and creative appropriation of aspects of social and material reality. As a methodological procedure, the research was qualitative, descriptive, with a sample formed by students of public administration in Ceará. The results found a greater relationship between meanings and self-promotion values, with emotional reward. The security value reflected an important volume of citations, related to financial stability and life-work projects.

The innovation process, such as the enrichment of company assets, is the subject of the third article in this edition of ReCaPe. The text "Scientific production in operations management with a theme focused on Knowledge Management", by professor Deborah Martins de Sousa Nolasco, from SENAI, Bahia, by professor Ismael de Mendonça Azevedo, from Universidade Potiguar and from the teachers of the Post- Graduation in Administration also from Potiguar University, Luciana Gondim de Almeida Guimarães and Laís Karla da Silva Barreto, aims to elaborate an overview of scientific production in Operations Management with a theme focused on Knowledge Management, between the period 2007 to 2016 . The The main justification of the study was the perception that the operational environment is an adequate environment for the development of research regarding knowledge management, since knowledge to be created needs a place and a context, in addition to the relationship between individuals. This is where information has meaning through interpretation to become knowledge. It is in the structure of operations within the company that there is a large component of tacit knowledge. The authors used the bibliometric technique. The results show 531 works, prepared by 1349 researchers that are spread over more than 98 countries. The United Kingdom, United States 
and China lead the ranking of productivity, and quantitative of researchers, among other results. The theme of Operations Management from the perspective of Knowledge Management has still been little explored, with only 16 related works.

The fourth article in this edition of ReCaPe, "The impact of Employer Branding in attracting and retaining talent", by researchers Amanda Setin Correa, Amanda Setin Correa, Sarah Alves Batista, all from Fundação Escola De Comércio Álvares Penteado - FECAP and the teacher Fabricio Stocker, visiting professor at Amsterdam Business School - University of Amsterdam, aims to understand the influence of an innovative attitude, that of Employer Branding on organizational practices for attracting and retaining workers and how this concept can help in the identification of cultural profiles and traits. The research, with a qualitative profile, used semi-structured interviews and the content analysis technique; the sample favored both different specialist profiles and generational identifications. The research results suggest the identification of three profiles in the job market, with different impacts, especially in generations $\mathrm{X}$ and $\mathrm{Y}$. The study also showed that a considerable part of organizations is in an initial stage of knowledge on the subject and that many of them unconsciously employing branding actions, especially in terms of attracting and retaining talent.

The innovation process may have its own characteristics in the public sector. The fifth article of this edition, "Reactions to change: implantation of the electronic point in a City Hall", by researchers Marcela Carolina Campos de Faria and Débora Dias Resende, both from the Federal University of Viçosa and Adriana Ventola Marra, Professor of Administration also at the University Federal de Viçosa aims to analyze the behavior of public servants in the Alfa city hall, in the face of a significant impact change: an electronic point. In theoretical terms, the study is cautious on the topic of organizational change. When searching for the keyword "organizational change" in the SPELL database, in the period 2010-2019, seventy-five articles were found. After reading the abstracts, it was noticed that only seven specifically analyzed the reactions to the change of civil servants in public institutions. The method used was a descriptive case study. The sample was defined by the accessibility criterion and the data collection techniques used in this study were: participant observation, documentary research, semi-structured interviews and questionnaires. The survey results showed that, regarding the reactions of public servants to the change process, the averages of the formal and informal sources are in the moderate Concordance range. The dispersion measure shows that public servants are very close to the levels of moderate agreement regarding the institution's form of communication. The high agreement for moderate consistency suggests that these servers saw the change as an opportunity, or that they could not differ whether it was positive or negative.

The sixth article in this issue, "Organizational behavior and sustainable behavior at work: evidence from the public sector" by professors Clayton Robson Moreira da Silva and Laís Vieira Castro Oliveira, from the Federal Institute of Education, Science and Technology of Piauí (IFPI), and rese- 
archers Diego Oliveira Bona, João Antonio do Nascimento Oliveira and Thiago Christiano de Araújo Pinheiro, from the same institution, aim to analyze the organizational commitment and sustainable behavior at work, verifying the influence of the commitment link in the pro-environmental actions of public servants in the Desktop. In methodological terms, a survey was used, with questionnaires to the employees of a federal educational institution, located in the State of Piauí. The results of the study showed that the individuals who showed the greatest emotional commitment also showed the greatest environmental behavior at work, denoting that the organizational bond influences sustainable behaviors at work.

The seventh article of this edition "Perception of financial institution managers on the importance and mastery of managerial skills", by Carlos Costa, professor in the Graduate Program in Administration at the School of Administration at IMED Business School 1, by researchers Ana Paula Pessotto, Claudionor Guedes Laimer, André de Oliveira Santos and Professor Viviane Rossato Laimer, from the Federal University of Fronteira Sul, aim to assess the mastery of managerial competences, to identify in these managers effective assimilation of models proposed by literature, as well as the capacity classify them by degree of importance. With a relevant complementarity: to investigate the individual perspectives of these managers. The research, with a quantitative profile, in a survey format with the application of a questionnaire for the collection of primary data, had a sample built covering the entire national territory. The survey results showed, first, that women are more educated among these managers, and that the longer the service in the financial institution, the greater the probability of promotion to the position of manager. Regarding the following competencies: entrepreneurship, perception and judgment and global vision, it is observed that managers preserved significant averages. However, the competences evaluated as the most important and under which managers say they have greater mastery, mostly congregate social competences, those that prioritize personal relationships.

The article that closes this edition of Revista de Carreiras e Pessoas establishes an important link between innovation, job satisfaction and professional performance. The study "Professional Development, emotional exhaustion and intention to stay in organizations" by Professor Harrison Bachion Ceribeli at the Federal University of Ouro Preto and researcher Luana Karine do Carmo Silva, from the same institution, aims to analyze the influence that development opportunities professional exercise on the emotional exhaustion of workers and their intention to remain in the organization. The research, with a quantitative profile, in survey format and the sample brought together professionals from three cities in Minas Gerais, using the Structural Equation Modeling technique to analyze the collected data. The research results showed the impossibility of confirming that expanding the worker's autonomy and the variety and complexity of the work performed directly influence the intention to remain in the organization. However, it was to prove the negative influence of practices 
aimed at promoting human development in the organizational sphere on the emotional exhaustion of the worker. It was also possible to confirm that training actions, career growth opportunities and autonomy at work are capable of reducing worker exhaustion.

Good reading!

Leonardo Trevisan, Elza Veloso and Joel Dutra

Publishers 